\title{
EVALUATING THE ECONOMIC COST OF ENVIRONMENTAL MEASURES IN PLANTATION HARVESTING THROUGH THE USE OF MATHEMATICAL MODELS*
}

\author{
FELIPE CARO, RODRIGO ANDALAFT, XIMENA SILVA, \\ ANDRES WEINTRAUB, PEDRO SAPUNAR, AND MANUEL CABELLO \\ Departamento de Ingenieria Industrial, Universidad de Chile, Republica \#701, \\ Santiago, Chile \\ Consorcio Nacional de Seguros Vida, El Bosque Sur \#130-6 Piso, Las Condes, \\ Santiago, Chile \\ ENDESA, Avda. Cuarto Centenario No. 90, Departamento 1901, Las Condes, \\ Santiago, Chile \\ Unidad de Planificacion de la Produccion de Bosques Arauco S.A., Los Horcones s/n, \\ Arauco, Chile \\ Forestal Millalemu, KM 12 Camino Coihueco Chillan, Chile
}

\begin{abstract}
An important issue being discussed for Chilean pine plantation policies is the application of environmental protection measures when managing its timber areas. Typical measures, already in place in more developed countries, include imposing riparian strips and protecting fragile soils from the use of heavy machinery. While environmental protection measures have been considered vital for decades, so far there has been almost no attempt to quantify both the benefits and costs of these measures. This paper attempts to measure the costs associated with the main measures which can help both the forestry firms and the government evaluate the cost impact of the new environmental protection regulations being studied. The analysis for different environmental scenarios is carried out by modifying a mixed integer LP, currently used for tactical planning by one forestry firm.

(FOREST MANAGEMENT; ENVIRONMENT; PLANNING MODEL)
\end{abstract}

\section{Introduction}

Chile has an important forestry industry in its southern region. It is based mostly on pine plantations, with a rotation of about 25 years, integrated with industrial plants (sawmills, plywood, pulp) to fully use the different parts of the trees. The lower part with wider diameter usually goes for export or high quality saw products; the middle part is used at local sawmills; and the upper part, of lowest diameter, is used at pulp mills. Downgrading is possible where higher diameter logs can be used for purposes requiring smaller diameter, with a loss in value of timber.

We start by first describing the situation of a typical forest firm. The holdings of Sociedad Forestal Millalemu (which we will refer to as Millalemu) are composed of 17 forest areas of different sizes ranging from 65 to 560 hectares. Within each forest area, homogeneous stands

*Received April 2002; revision received January 2003; accepted August 2003. 
are defined, based mostly on tree age, location, and site quality. Forest areas are accessed by public roads, usually paved. However, within the areas, roads are the firm's responsibility, which builds either lower cost dirt roads that can only be used in the dry summer season or higher priced gravel roads that can be used year round. Upgrading from dirt to gravel is possible. All road building and upgrading is carried out in the summer season. Harvesting is carried out by skidders in flat areas and by towers or cable logging in steeper areas.

For the last 5 years, Millalemu has used OPTIMED, a computational system based on a LP model with $0-1$ variables to support tactical decisions on a 2- to 5-year horizon.

The main decisions to consider in the model are:

i) Timing for harvesting of each stand.

ii) Volumes to be harvested and transported to meet estimated demands. Future demands are defined through lower and upper bounds based on firm orders and forecasts of future orders.

iii) Road building or upgrading to access stands.

iv) Volume of timber to store (in a stocking yard) from Summer to Winter.

The use of the model has allowed important improvements in the quality of solutions, leading to improved decisions on when to harvest each area and when to build roads in time to provide access needed for harvesting (Epstein, Morales, Seron, and Weintraub 1999; Andalaft et al. 2003).

Imposing constraints on harvesting practices to protect the environment, wildlife, water quality, soil, and scenic beauty has been a major concern for at least the last three decades for native forests and lately for plantations. In the case of native forests, in particular in North America and Europe, environmental and wildlife protection in its different aspects has assumed a vital importance, often preceding that of timber production. In plantations, the economic performance is obviously paramount. However, environmental concerns have taken an increasing importance, in particular to protect soil and water quality. Some issues prevalent in native forest, such as protecting wildlife, are not as vital for the case of plantations. We considered typical measures already taken for plantations in more developed countries, such as the U.S. or New Zealand (Weintraub, Epstein, Murphy, and Manley 2000), complementing them with a parallel study in Chile, and analyzed their implementation in our case.

The main measures considered are:

i) Not harvesting on a width alongside rivers or watercourses, to avoid logs, debris, or sediment falling into the water. These are called riparian strips.

ii) Leaving strips of standing trees alongside roads to preserve scenic beauty. Note that once the trees planted after harvesting behind the strip grow to a certain height, the trees in the strip can be harvested. In this form, the view from the road will always perceive trees.

iii) Heavy equipment like skidders produce damage to soils, by compacting it and creating erosion. This is particularly serious for more fragile soils. Typical soil protection measures consider using cable logging or towers instead of skidders for fragile areas and not harvesting at all for highly fragile areas.

iv) Harvesting when raining causes erosion, so minimizing harvest in the rainy season is an important protective measure.

v) For native forest in particular, a series of spatial considerations have been imposed to protect wildlife and scenic beauty. Mainly, such measures include limiting the size of patches of contiguous area that are harvested and creating patterns of blocks of mature trees. These configurations are friendly to animal species. There is a wide body of literature describing the application of spatial measures and how to find solutions in these situations. For example, Murray and Church (1995) consider maximum size of contiguous harvested areas and Hof and Bevers (2002) also consider wildlife conservation. Barret, Gilles, and Davis (1998) analyze the consequences for private timber holdings as they vary the maximum size of 
contiguous area harvested and how soon afterwards a neighboring area can be harvested (called green-up).

While there are clear environmental benefits associated with these measures, it has been complicated to measure them quantitatively, mainly due to the difficulties in obtaining exact impact figures in the effects they produce and the non-monetary value associated with them.

There has also been little effort to determine the cost associated with these measures, expressed as a decrease in net present value or in timber yields. We feel it is important to develop a tool which can quantify these effects. This tool can easily be extended to consider different situations both for plantations and also for native forests. For example, a model developed for the U.S. Forest Service (Weintraub et al., 1994) to handle decisions on road building and harvest sequencing can be modified in a process similar to the one presented here to evaluate different environmental measures, such as those described above, and others more directed to native forests, such as different variations of spatial considerations.

The consideration of environmental issues in Chile became more intense in the last decade or so. There have been two driving forces behind this. The first is internal. There has been an increasing awareness of environmental values and the need to preserve biodiversity. The government has created offices with increased power that regulate environmental issues.

For the first time, in the last decade important investments have been held up because of environmental questions. For example, a U.S. \$500 million investment in a pulp plant was delayed over 5 years until several important environmental issues were settled. In 2000, the government named a well known active environmentalist as head of the Environmental Commission, a subcabinet level position. However, due to the slowing down of the economy in the last 4 years, this impetus has lost some of its force.

The government has been less active in measures that might impede growth and job creation. The second driving force is the global economy and its imposition that all countries preserve the environment. For example, the ISO 14,000 standards are oriented toward environmental measures, and firms wishing to export must sometimes comply with these or similar requirements.

The environmental factor has played a particularly important role in the forestry sector. Just 20-30 years ago, in considering Chile's relative advantages to produce and export pulp, one advantage mentioned was that, as a developing country, Chile need not worry as much about the costs involved in reducing the contamination caused by pulp plants. Those environmental constraints were considered a privilege for developed countries. Naturally, there has been a complete change in this perspective. The need to preserve forest soils grew both as an awareness of the benefit for the forestry companies of increasing the value of their holdings, by having better quality lands for future harvests, as well as the realization that the political climate was increasingly pointing toward more active environmental protection. The project described here grew out of this awareness. Firms became interested in determining the trade offs between measures to preserve and protect the environment both for considerations of value of their own holdings, and to prepare themselves for the expected political discussions on measures and regulations that the government is likely to impose in the future. Implementing environmental measures is a slow political and cultural process. The results of this project can permeate the culture of forestry firms in relation to harvesting practices that have good "trade off" values, for example, by pushing toward more intensive use of cable logging in fragile areas. In political terms, the slowing down of the economy has postponed the internal political discussions of regulations, which will take years to mature. What has moved to the front burner now has been the international political climate for environmental protection. Chile exports about $90 \%$ of its timber products and, increasingly, the markets in developed countries are erecting "green barriers," that is, they allow only imports which comply with environmentally safe practices, from the forests to the plants. For example, Home Depot will not purchase wood products which do not come from environmentally certified forests. In 2002, Chile signed Free Trade Treaties with the European Union and the 
U.S. While this is naturally a privilege for Chile, it also entails added responsibilities, which include stricter compliance with environmental concerns. At present, there are several important international NGOs, non-governmental organizations, competing to establish their certification procedures. The most important are FSC, the Forest Stewardship Council, PEFC, The Pan-European Forest Certification, SFI-SFB, The U.S. Sustainable Forest InitiativeSustainable Forest Bureau, and CSA, The Canadian Standards Association. One of the authors of this paper is a member of the Commission for Forest Certification, which is in charge of producing the manual of rules for certification of forests in Chile. This manual, now completed, will be compared and validated with other international ones, so that Chilean exporters can access foreign markets with no hindrances. This process has already started. Environmental manuals are designed in a more general framework than governmental regulations. For example, where a government regulation might impose a riparian strip of 50 meters to protect a water course, an Environmental Manual will tend to emphasize in general the need to protect water quality and the type of measures that can be taken. In terms of certification, the results of the analysis of trade offs presented in this paper can be helpful in the future, when the considerations in the manual, yet to go through an approval and validation phase, start taking concrete forms. A main contribution of this paper is to allow all stakeholders to evaluate the cost of specific, quantitative environmental measures through the use of mathematical models.

In a study funded by the Science and Technology Council of Chile, which supports joint University-Enterprise applied research, a group of academics from the University of Chile and representatives from the major Chilean forest firms (Arauco, Mininco, Bío Bío and Millalemu) carried out the analysis described in this paper. Millalemu was chosen for the test study. In a parallel study (De la Maza 1997), the main environmental protection measures were identified as those described above in points i) through iv). Spatial constraints, such as described in v), were not included, as these were considered not yet pertinent to Chilean requirements.

In New Zealand, similar environmental measures were imposed for plantations through the 1991 Resource Management Act, and a posteriori evaluations showed significant impacts in loss of net revenues and timber yields as a consequence (Weintraub et al. 2000).

In Section 2, we present a version of the model in the OPTIMED system and its use. In Section 3, we discuss in detail the environmental measures considered and how they were included in the tactical model. In Section 4, we detail the Millalemu instance, the different scenarios considered, and the computational results of the basic model, while Section 5 covers sensitivity analysis, and Section 6 gives the conclusions.

\section{The Mathematical Model}

We present in this section the basic model presently used by Millalemu for tactical decisions. We concentrate on the part of the model that will be used in the evaluation process of environmental measures. A complete version of the model as well as algorithmic details of its solution are described in Andalaft et al. (2003).

\section{Indices}

$t$ or $u$ : a time period, which can refer to Summer or Winter season, $t=1, \ldots T$

$s$ : a stand mature for harvesting

$i$ or $j$ : an origin node of the road network, to which one or more stands provide timber

$m$ : a destination node for timber products

$l$ : a machinery type

$r$ : a road standard, dirt or gravel

$k$ : timber product, in this case considered aggregated into export, sawmill, and pulp quality

(ij): a road in the network 


\section{Decision variables}

$X_{l s t}:$ hectares of stand $s$ harvested in period $t$ with machinery $l$ (Ha)

$Y_{i t k}$ : volume of timber product $k$ obtained through origin $i$ in period $t\left(\mathrm{~m}^{3}\right)$

$F_{r(i j) t k}$ : flow of timber product $k$ on road $(i j)$ built to standard $r$ in period $t\left(\mathrm{~m}^{3}\right)$

$Z_{m t k}$ : volume of product $k$ sold at destination $m$ in period $t\left(\mathrm{~m}^{3}\right)$

$W_{r(i j) t}: 1$ if road (ij) is built to standard $i$ in period $t$ (Summer); 0 otherwise

\section{Parameters}

$a_{s t k}$ : volume of timber product $k$ obtained in stand $s$ if harvested in period $t\left(\mathrm{~m}^{3} / \mathrm{Ha}\right)$. These values are obtained through a Timber Yield Simulator, which can predict future harvest yields of different products.

$A_{l s}:$ number of hectares in stand $s$ that can be harvested with machine type $l$

$U_{(i j) r t}$ : flow capacity on road $(i j)$ of standard $r$ in period $t(\mathrm{~m} 3 /$ period). This capacity constraint is usually not active as it is much larger than actual flows. Note that no flow is possible on dirt roads in Winter.

$Z_{m t k}^{L O W}:$ lower bound on the sales of product $k$ made at destination $m$ in period $t$

$Z_{m t k}^{U P}$ : upper bound on the sales of product $k$ made at destination $m$ in period $t$

\section{Constraints}

1. Production by ORIGIN

$$
\sum_{s \in[i]}\left(a_{s t k} \cdot \sum_{l} X_{l s t}\right)=Y_{i t k} \text { for all } i, t, k
$$

where $[i]$ is the set of stands that contribute to origin $i$. In each period $t$, for each product $k$ the total outflow from origin $i$ is the sum of production from all stands associated with it.

2. ARea Per STAND

$$
\sum_{t} x_{l s t} \leq A_{l s} \text { for all } s, l
$$

The total area harvested with a certain type of machinery $l$ on a certain stand $s$ cannot exceed the available area. This is defined for each stand and machine type. Each area is to be harvested with one specific type of machinery.

3. Flow COnSERvation. This set of constraints insures flow conservation of each product harvested in stands. Thus, volume of product $k$ harvested in a given stand $s$ goes through existing roads in the network to final destinations, which can be the pulp plant, sawmills, or ports for export. The constraints allow for downgrading, as export timber can be delivered to sawmills or the pulp plant, and saw timber can be delivered to the pulp plant. Stocking yards can be used to stock timber, for any product, from Summer to Winter, up to the capacity of each stocking yard.

\section{Bounds on SALES (DEMAND CONSTRAints)}

$$
Z_{m t k}^{L O W} \leq Z_{m t k} \leq Z_{m t k}^{U P} \text { for all } m, t, k
$$

where for each product and period lower $Z_{m t k}^{L O W}$ and upper $Z_{m t k}^{U P}$ bound on amounts to be sold can be defined.

5. ROAD BUILDING

i) $\sum_{k} F_{r(i j) t k} \leq U_{(i j) r t} \sum_{u \leq t} W_{r(i j) u}$ for all $(i j), t, r$ 
For a non-existing road, it must be built in a given standard $r$ by period $t$ to allow flow up to its capacity.

$$
\text { ii) } \sum_{r} \sum_{t \leq T} W_{r(i j) t} \leq 1 \quad \text { for all }(i j)
$$

Any road can be built at most once through the horizon $T$.

6. ROAD UPGRADING. For existing roads, there is a defined capacity. Upgrading from dirt to gravel, which is carried out in Summer, is also a possibility.

7. Fixed costs for harvesting are handled through constraints which state that if a stand is harvested at all it has to be done to at least a minimum area. This avoids harvesting too small areas.

$$
X_{l s t}, Y_{i t k}, F_{r(i j) t k}, Z_{m t k} \geq 0, W_{r(i j) t} \in\{0,1\}
$$

\section{Objective Function}

We need to maximize net present value. The components of the objective are: income due to sales $Z_{m t k}$ at market prices and costs due to: harvesting, transportation, road building and upgrading, and timber stocking.

This model has been in use for about 6 years in Millalemu (Epstein et al. 1999; Andalaft et al. 2003). It supports yearly planning decisions in relation to stands to harvest, volumes of timber to produce and send to markets, roads to build or upgrade, and stocks of timber to hold from Summer to Winter.

It has also been used to evaluate the purchase rights of harvesting, that is, the right to harvest a timberland belonging to a third party; and returning the land to the owner after completing the harvest. By running the model with and without a particular timberland, it is possible to estimate its value to Millalemu, which will depend in part on logging distances and tree ages.

This is the model our study is based on. At Millalemu, the model is presently solved using a commercial LP package with heuristics to round off integer variables. More exact and faster solutions can be obtained through considering additional algorithmic enhancements, such as strengthening the LP formulation, lifting, and Lagrangean relaxation. This approach was very successful in computational tests (Andalaft et al. 2003).

We note that this model has important similarities to previous tactical models developed for the U.S. Forest Service (Kirby, Hager, and Wong 1986; Weintraub et al. 1994), but also has differences, mainly in the time horizon considered (a few years including seasons versus decades), introducing several types of products, single species plantations compared with native forests, and assigning fixed costs to harvest areas versus the described spatial constraints such as maximum contiguous area to be harvested considered in native forests. As mentioned before, a similar process for evaluating the costs associated with different environmental measures by modifying the basic model can be carried out in the case of the U.S. Forest Service model, as well as in many other situations.

\section{Environmental Measures and Impact on Planning Model}

In De la Maza (1997), impacts due to harvesting practices were determined as well as a set of environmental measures considered adequate for reducing these impacts. These measures are consistent with practices adopted in other countries with similar forest characteristics, such as New Zealand (Weintraub et al. 2000). The following were considered the basic environmental measures in De la Maza (1997) and were implemented in the tactical model presented in the previous section.

- Avoid harvesting with heavy machinery on fragile soils. Highly fragile soils cannot be harvested at all.

- Leave strips of standing trees on public roads to preserve scenic beauty. 
- Leave riparian strips along watercourses to protect water quality. An alternative measure, based on protection barriers was also introduced.

- Favor harvesting in the drier Summer season.

We did not consider explicitly environmental measures related to road building, as test runs showed that taking special care to impose measures related to the design of roads, such as avoiding building roads parallel to slopes or on fragile soils, did not significantly affect the value of the solutions. So, while these measures need to be implemented, it is not necessary to introduce modifications in the model for this purpose.

The way to implement these measures is described below. Details are given in Caro (1999). We note that we could introduce other environmental measures through other modifications of the model. For example, some spatial constraints as those described in point v) of Section 1 (Introduction) have already been considered in many studies (Weintraub et al. 1995; Martell, Gunn, and Weintraub 1998).

\section{1) Avoid harvesting on fragile areas}

Areas with steeper slopes, fragile types of soils, and those subject to heavy rains are more prone to degradation when harvested. These areas should be harvested via aerial systems: tower or cable logging instead of heavy land machinery, such as skidders. In more extreme cases, harvesting should be avoided altogether. A first step was to construct a Fragility Index (FI), based on the work by Gayoso (1997) in Chile, in order to classify all areas into high, medium, or low level of fragility, and take measures accordingly; that is, do not harvest areas with high fragility, use only cable logging for areas with medium fragility, and allow all harvesting machinery in areas of low fragility.

The model proposed by Gayoso calculates degradation indices, risk of slippage, land erosion, land compacting, and loss of topsoil based on six attributes: land density, internal drain age, profile depth, slope, soil texture, and level of rains. Based on the values of the attributes and formulas for each risk index, a global value for fragility (FI) is determined between 0 and 10, where 10 indicates the highest fragility. The definition of high, medium, and low fragility can be parameterized along the values $(0-10)$.

In a first approach, based on the definition by Gayoso (1997), values in the range 0 to 5.9 were considered low fragility, 6.0 to 6.9 medium fragility, and 7.0 to 10.0 high fragility.

The model was modified accordingly by recalculating the parameter $A_{l s}$, the area available to harvest with machine type 1 in stand $s$. In this case, areas with fragility 6.0 to 6.9 were compelled to be harvested with cable logging, irrespective of slope considerations, while areas with fragility 7.0 to 10.0 were excluded from harvesting. The values that define level of fragility were modified parametrically to test different scenarios. Note that the timber of areas not harvested due to soil fragility is also lost in the long run.

\section{2) Scenic strips along public highways}

In order to define these non-harvested strips along public roads, the density of the forest areas along the roads was considered.

For higher density areas ( $>700$ trees/Ha) a strip of 20 meters along the road was proposed, for medium density (400-700 trees/Ha) a strip of 40 meters was used, and finally a strip of 60 meters was used for low density areas $(<400$ trees/Ha).

Note that strip width can be parameterized, and that these harvesting areas are not lost, only postponed until the newly planted trees behind the strip grow, thus delaying these volumes beyond the horizon of our model.

To account for these strips, the parameters $A_{l s}$, the area harvested in stand s with machinery $l$, is modified to:

$$
A_{l s}=A_{l s}-\sum_{(i j)} \sum_{d} \text { Length }_{l s(i j) d} \text { Strip }_{d}
$$


where Length $_{i s(i j) d}$ is the length of the segment of road (ij) that crosses stand s through area that can be harvested with machinery 1, and Strip $p_{d}$ is the strip width for tree density d. The new parameter $A_{l s}$ takes into account strips excluded from harvesting.

\section{3) Riparian strips}

To decrease water contamination and sedimentation, vegetative strips are left along watercourses. These strips are not harvested.

Two types of watercourses were defined: type 1, which do not have other tributary watercourses (affluents); and type 2, those that do have affluents and are considered more important. Different total widths, $F_{g}$, of the riparian strips were introduced into the model by modifying the $A_{l s}$ parameters for the set of water courses w, in a similar way as done for road strips.

$$
A_{l s}=A_{l s}-\sum_{w} \sum_{g} A G_{l s w g} \cdot F_{g}
$$

where $A G_{l s w g}$ is the length of watercourse w of type $g$ that crosses stand s through area that can be harvested with machinery 1 , and $F_{g}$ is the strip width.

In a first run, strips of 15 and 30 meters were used for watercourses type 1 and 2, respectively.

\section{4) Reduce harvesting in the rainy season (Winter)}

The intention of this measure is based on the higher degradation that occurs when harvesting in rain-soaked soils. This is particularly negative for fragile soils. To consider this effect in the model, one possibility is to specify for each stand, depending on its soil fragility, a maximum amount of area that can be harvested in Winter. This approach seems natural but has the inconvenience that it is not clear to managers how to define upper bounds for Winter (and the model can end up being too restrictive). For this reason, a relative (rather than absolute) measure was chosen which limits the amount harvested in Winter to a fraction of what was harvested in Summer. This type of measure is much easier to implement in practice. In particular, an average Fragility Index was calculated for each stand. Then, for each machinery type 1, three parameters were defined: $\operatorname{high}_{1}, \operatorname{med}_{1}$, and $\mathrm{low}_{1}$. Each one indicates the maximum proportion of hectares to be harvested in Winter with that machinery as compared with Summer, for a stand with average Fragility Index in the high, medium, and low range, respectively (we used the same fragility ranges as in the first environmental measure). Naturally high $1<\operatorname{med}_{1}<\operatorname{low}_{1}<1$, as for example in the case of high fragility soils, the fraction of area harvested in Winter compared with Summer should be the lowest. Finally, new constraints were introduced. For stands with high average Fragility Index within the same forest area:

$$
\sum_{s} X_{l s t} \leq h i g h_{l} \cdot \sum_{s} X_{l s(t-1)} \quad \text { for all } l, t=\text { Winter, and }(t-1)=\text { Summer }
$$

These constraints limit harvesting in Winter to a fraction of the Summer harvest. Similar constraints were developed for stands with medium or low (average) fragility. Table 1 indicates the fractions used depending on the average Fragility Index.

\section{The Modified Tactical Problem}

We present next an analysis of the case study. We considered those holdings of Millalemu which could supply timber for harvesting in the next 3 years. These constitute 29 separate areas with a total of 4,316 hectares, spread over 3 of Chile's southern regions. Table 2 shows the characteristics of the 14 largest of these 29 areas. 
TABLE 1

Fraction of Ratio of Winter/Summer Harvesting by Machine Type and Fragility Index

\begin{tabular}{llc}
\hline Average Fragility & Machinery & Fraction (Winter/Summer) \\
\hline High $(>7.0)$ & Skidder & 0.0 \\
Medium (6.0-7.0) & Tower & 0.2 \\
& Skidder & 0.5 \\
Low $(<6.0)$ & Tower & 0.7 \\
& Skidder & 0.8 \\
& Tower & Free \\
\hline
\end{tabular}

The resulting model has about 9,000 continuous variables, 1,500 binary variables, and 15,000 constraints.

The model requires as input about 14,700 parameters of which 4,932 are altered by the environmental measures. About one-quarter of these have to be calculated and entered into the model manually. A geographic information system (GIS) provides most of the remaining information. A modification was made to account for geographic locations: as defined, stands are homogeneous areas in a same zone, but may correspond to disjoint areas. Since connectivity is important for the purpose of the environmental measures and the tactical model, we used polygons, derived from a GIS. Polygons are defined as a connected area belonging to a unique stand, and also respecting natural limits such as roads, ravines, rivers, etc. In this form, a stand is composed of one or more polygons. In the case of Millalemu, 250 stands led to 1,120 polygons going from 0.1 to 30 hectares. Polygons are then associated to origin nodes from which loading will be carried out in the model.

In setting up the parameters of the model, a grid form of 0.25 hectares was defined and used at the level of the polygons to handle needed characteristics of fragility to modify parameters corresponding to number of hectares available for harvesting or to assign to cable logging.

As described before, 29 areas were considered with 4,316 hectares. In order to appreciate the relative impact of the environmental measures, it is important to notice that $5 \%$ of this area had Fragility Index equal or higher than 7, 25\% between 6.0 and 6.9, and the remaining is below 5.9. The length of public highway that required non-harvested strips was $8.4 \mathrm{~km}$. The length of watercourses type 1 and 2 was $77 \mathrm{~km}$ and $17 \mathrm{~km}$, respectively.

TABLE 2

Description of the 14 Largest Areas of Millalemu

\begin{tabular}{|c|c|c|c|c|c|c|c|}
\hline$\#$ & Name & $\begin{array}{l}\text { No. of } \\
\text { Stands }\end{array}$ & $\begin{array}{l}\text { No. of } \\
\text { Origins }\end{array}$ & $\begin{array}{l}\text { Area } \\
(\mathrm{Ha})\end{array}$ & $\begin{array}{l}\text { No. Dirt } \\
\text { Roads }\end{array}$ & $\begin{array}{l}\text { No. Gravel } \\
\text { Roads }\end{array}$ & $\begin{array}{c}\text { No. of } \\
\text { Potential Roads }\end{array}$ \\
\hline 1 & El Tollo & 14 & 11 & 165.5 & 4 & 9 & 0 \\
\hline 2 & El Guanaco & 16 & 13 & 310.7 & 8 & 8 & 0 \\
\hline 3 & Trehualemu & 9 & 8 & 160.1 & 8 & 0 & 0 \\
\hline 4 & Nueva Etruria & 29 & 27 & 559.5 & 12 & 15 & 2 \\
\hline 5 & Llancacura & 12 & 11 & 140.8 & 10 & 0 & 1 \\
\hline 6 & Quiriquino & 19 & 14 & 65.1 & 12 & 0 & 9 \\
\hline 7 & Lomas de Polcura & 5 & 4 & 398.6 & 4 & 10 & 0 \\
\hline 8 & Oyetrahue & 10 & 7 & 189.0 & 8 & 0 & 2 \\
\hline 9 & Los Corrales & 6 & 5 & 370.7 & 5 & 0 & 0 \\
\hline 10 & San Fernando & 9 & 7 & 179.8 & 6 & 0 & 2 \\
\hline 11 & Porvenir 3 & 4 & 3 & 121.4 & 1 & 0 & 2 \\
\hline 12 & Llohue & 9 & 8 & 526.7 & 8 & 0 & 0 \\
\hline 13 & Los Copihues & 10 & 8 & 301.5 & 9 & 0 & 0 \\
\hline \multirow[t]{2}{*}{14} & Santa Elisa & 12 & 10 & 161.1 & 11 & 0 & 1 \\
\hline & TOTALS & 164 & 136 & $3,650.5$ & 106 & 32 & 19 \\
\hline
\end{tabular}


Once the model was set up, we considered a base scenario, which is the original model with no environmental constraints. A horizon of 2.5 years divided into 5 semesters was chosen. A discount rate of $8 \%$ was used, and bounds on sales (demand) for export, saw timber, and pulp, corresponding to Millalemu's 6 final destinations, were defined. Projection of future demand is important in decision making. This demand is composed of known future sales, such as the known requirements of a pulp plant, and estimates of demands to export either as logs or as more elaborate products along the supply chain such as saw timber or boards. As exports constitute $80 \%$ to $90 \%$ of sales, in competition with other producers worldwide, estimating future demand is not exact.

Thus, when planning, firms usually establish lower and upper bounds on future sales to reflect market uncertainties. Lower bounds include existing contracts plus "almost sure" future sales, while upper bounds reflect a mixture of perceived optimistic sales scenarios as well as the need to preserve standing timber for periods beyond the planning horizon. As this is a tactical model of relatively short horizon, it should not allow harvesting an excessive amount of timber within its horizon.

Experiments were performed on a 300-MHz Pentium II PC with 512 MB of RAM. The original model plus the environmental constraints and additional strengthening constraints (see Andalaft et al. 2003) were coded in GAMS, and CPLEX 6.0 was used as a solver. A 3\% error bound was accepted in the MIP runs (in most runs, the final gap was way below 1\%). The run times for most scenarios were less than 1,000 seconds. The exceptions were those scenarios that included constraint R4, restricting winter harvests, which usually took 10 times more. An explanation for this high increase in computer effort is possibly that adding a type of constraints such as (R4), which links output in two successive periods as constraints that become active, can increase solution times. This happens as fixing one fractional variable to integrality often just leads to another variable becoming fractional and thus many additional branchings are carried out which are of marginal value to reaching an optimal solution. This problem has been approached successfully in other settings by "elastisizing" these constraints, e.g., allowing small penalized violations of the constraints (Ehrgott and Ryan 2003). Since these models need to be solved just a few times, and computer times were moderate for our experiments, efficient problem solving was not in the essence of this research, and we did not carry out tests to verify if the "elastisizing" approach reduced computer times in our case.

We designed a set of runs to represent the basic environmental measures described. We first tested those measures applying them each separately in order to have a first analysis of the impact on net revenue of each measure and timber production. For riparian strips alongside watercourses, we analyzed two scenarios. One being more demanding in terms of defining strips for all watercourses, while the other only considered strips for the more important watercourses. After the scenarios for individual measures were tested, we analyzed scenarios for combinations of the measures which individually had proved to cause higher cost variations. A final run was considered implementing all measures simultaneously, to obtain the highest cost scenario. A complete list describing all scenarios is given below:

Scenario R1. Use only cable logging on areas with fragility index (FI) in the range (6.0-7.0) or with slopes above 30\%. Do not harvest areas with FI above 7.0.

Scenario R2. Have non-harvested strips alongside public roads, as described in the previous section.

Scenario R3. Define riparian strips alongside watercourses of 20 meters for water-courses type 1 and 40 meters for type 2.

Scenario R3B. Define riparian strips of 30 meters only for watercourses type 2.

Scenario R4. For each zone, restrict Winter harvesting according to fragility, as defined by Table 1.

Scenario R13. Apply simultaneously scenarios R1 and R3.

Scenario R13B. Apply simultaneously R1 and R3B. 
Scenario R14. Apply simultaneously R1 and R4.

Scenario R34. Apply simultaneously R3 and R4.

Final Scenario. Apply simultaneously R1, R2, R3, and R4.

We note that in these scenarios the possibility of using a stocking yard was not enabled, as the present policy of Millalemu is not to use them. This condition was then relaxed in the sensitivity analysis of scenario R4.

Table 3 shows the results obtained for each scenario.

As can be seen, the basic scenarios that have highest impact are R1 (limit harvesting in fragile areas), R3 (riparian strips), and R4 (limit harvest in Winter). When all measures are applied jointly, there is a reduction of almost $12 \%$ in NPV.

We note that, in this case, the reduction in NPV is driven basically by higher costs. This is due to the upper bound on sales, which was binding in all scenarios, so the income is almost constant. In later runs, when this bound is removed, we will see that the impact of the measures on NPV increases significantly, as income is reduced. The increase in cost is mostly due to higher use of more expensive cable logging (because of fragility considerations) and increase of road upgrading when harvesting in Winter is restricted (since more stands need to be accessible and only gravel roads can be used in Winter).

Table 4 shows the total timber volume obtained in each scenario.

As explained, given the active upper bound on sales, the loss in timber volume is very low. Table 5 shows the variation in areas harvested under the different scenarios.

The results show that the measures which exclude most land from harvesting are R1 (no harvesting in highly fragile soils) and R3 (riparian strips). When all measures are considered, the total protected area corresponds to about $13.3 \%$ of the available land. On the other hand,

TABLE 3

Comparison of Different Scenarios

\begin{tabular}{|c|c|c|c|c|c|c|c|c|c|c|c|}
\hline & Base & $\mathrm{R} 1$ & $\mathrm{R} 2$ & $\mathrm{R} 3$ & $\mathrm{R} 3 \mathrm{~B}$ & $\mathrm{R} 4$ & $\mathrm{R} 13$ & R13B & $\mathrm{R} 14$ & R34 & Final \\
\hline NPV (U.S. \$1000) & 15,996 & 15,513 & 15,932 & 15,524 & 15,891 & 14,907 & 14,937 & 15,448 & 14,828 & 14,391 & 14,106 \\
\hline (\% variation) & 0.0 & -3.0 & -0.4 & -3.0 & -0.7 & -6.8 & -6.6 & -3.4 & -7.3 & -10.0 & -11.8 \\
\hline Cost (U.S. \$1000) & 22,625 & 23,129 & 22,662 & 22,982 & 23,728 & 23,755 & 23,728 & 23,063 & 23,819 & 24,285 & 24,482 \\
\hline (\% variation) & 0.0 & 2.2 & 0.2 & 1.6 & 0.5 & 5.0 & 4.9 & 1.9 & 5.3 & 7.3 & 8.2 \\
\hline \multicolumn{12}{|l|}{ Segregated Costs } \\
\hline Harvesting & 9,657 & 9,988 & 9,637 & 9,730 & 9,680 & 10,129 & 10,260 & 9,989 & 10,218 & 10,236 & 10,355 \\
\hline Internal Transport & 4,299 & 4,305 & 4,343 & 4,399 & 4,267 & 4,212 & 4,398 & 4,399 & 4,223 & 4,300 & 4,322 \\
\hline Road Upgrading & 777 & 881 & 784 & 815 & 812 & 1,474 & 930 & 854 & 1,417 & 1,515 & 1,548 \\
\hline
\end{tabular}

TABLE 4

Total Timber Volume Harvested $\left(M^{3}\right)$ Under Each Scenario

\begin{tabular}{lrrrrrrrrrrr}
\hline & \multicolumn{10}{c}{ Scenarios } \\
\cline { 2 - 11 } & Base & R1 & R2 & R3 & R3B & R4 & R13 & R13B & R14 & R34 & Final \\
\hline Total Production & 1,022 & 1,022 & 1,022 & 1,020 & 1,022 & 1,022 & 1,020 & 1,020 & 1,022 & 1,020 & 1,018 \\
Variation (\%) & 0.0 & 0.0 & 0.0 & -0.2 & 0.0 & 0.0 & -0.2 & -0.2 & 0.0 & 0.0 & -0.4 \\
Export & 507 & 507 & 507 & 505 & 507 & 507 & 506 & 505 & 507 & 506 & 504 \\
Sawmill & 361 & 356 & 359 & 354 & 356 & 357 & 356 & 361 & 353 & 352 & 354 \\
Pulp & 154 & 159 & 156 & 161 & 159 & 158 & 158 & 154 & 162 & 162 & 160 \\
\hline
\end{tabular}


TABLE 5

Areas Harvested Under the Different Scenarios

\begin{tabular}{|c|c|c|c|c|c|c|c|c|c|c|c|}
\hline & Base & R1 & $\mathrm{R} 2$ & R3 & R3B & $\mathrm{R} 4$ & R13 & R13B & R14 & R34 & Final \\
\hline Available Area & $4,316.1$ & $4,086.9$ & $4,293.0$ & $3,978.0$ & $4,214.5$ & $4,316.1$ & $3,763.6$ & $3,986.0$ & $4,086.9$ & $3,977.0$ & $3,740.8$ \\
\hline Protected Area & 0.0 & 229.2 & 23.1 & 338.2 & 101.6 & 0.0 & 552.5 & 330.1 & 229.2 & 339.1 & 575.3 \\
\hline Skidder Harvested Area & $2,247.7$ & $1,977.8$ & $2,253.1$ & $2,265.1$ & $2,256.6$ & $2,371.8$ & $1,989.2$ & $2,006.6$ & $2,061.6$ & $2,412.8$ & $2,010.3$ \\
\hline$\%$ Skidder Harvested Area & 80.2 & 69.1 & 80.7 & 80.9 & 80.9 & 79.9 & 67.8 & 69.9 & 69.1 & 80.7 & 67.4 \\
\hline Cable Harvested Area & 554.7 & 883.5 & 535.5 & 534.2 & 533.3 & 598.2 & 943.5 & 864.7 & 921.4 & 575.7 & 971.2 \\
\hline$\%$ Cable Harvested Area & 19.8 & 30.9 & 19.3 & 19.1 & 19.1 & 20.1 & 32.2 & 30.1 & 30.9 & 19.3 & 32.6 \\
\hline
\end{tabular}

the total harvested area increases. This is explained by the fact that riparian strips are usually more productive, so to compensate, more hectares of other areas need to be harvested. Note also that scenario R1 shifts about $10 \%$ of skidder harvesting to cable logging to reduce use of heavy machinery on fragile soils.

\section{Sensitivity Analysis}

After evaluating the impact of the basic scenarios, a second step was to analyze the sensitivity of the measures with respect to the parameter values, to see how robust were the results obtained.

\section{We analyzed the following variations:}

a) Modification of harvesting cost. To consider a range of harvesting costs, we reduced them from 8 to 5 U.S. $\$ / \mathrm{M}^{3}$ for skidders and from 9 to 7 U.S. $\$ / \mathrm{m}^{3}$ for towers, so the difference between the use of skidders and towers increased. Naturally, harvesting costs declined significantly, around 30\%, and the difference in cost between skidders and towers affected mostly scenario R1 (higher use of cable logging), but the differences were minor.

B) Sensitivity in the EVAluation of Fragility. This sensitivity analysis is important, as the basic definitions of high, medium, and low fragility were set somewhat subjectively. We considered 5 additional sets of fragility. Table 6 shows the results sorted according to the variation in NPV. In scenario R1-S1, the low to medium fragility limit is kept constant, with respect to scenario R1, and the medium to high is increased to 8.5. On the other side, in scenario R1-S5, the high to medium fragility limit is kept constant and the low to medium is reduced to 4.9. Scenarios R1-S2 and R1-S3, respectively, represent a downward and upward shift of the medium fragility range. Finally, scenario R1-S4 corresponds to a scenario in which the medium fragility range is symmetrically increased (with respect to scenario R1).

As Table 6 shows, the definition of fragility has an impact on NPV and protected area. As fragility becomes stricter, NPV is reduced up to $4.8 \%$, while the less strict definition leads to a loss of only $1.8 \%$. Harvesting costs increase when the limit between the low and medium fragility ranges is reduced. This is due to more use of cable logging. In the same way, protected area is larger when the limit between the medium and high fragility ranges is lower. Note that the bounds on sales imply no loss on timber production or revenues.

C) SEnSitivity In NON-HARVESTED STRIPS ALONG ROADS. The width of strips was varied from the original, which went from $20 \mathrm{~m}$ to $50 \mathrm{~m}$, depending on the tree density. Variations went from $10 \mathrm{~m}$ to $75 \mathrm{~m}$, with small impact, due to the relatively small amount of existing public roads: a little over $8 \mathrm{~km}$ for 4,316 hectares. 
TABLE 6

Sensitivity of the Definition of Levels of Fragility

\begin{tabular}{|c|c|c|c|c|c|c|c|}
\hline & \multicolumn{7}{|c|}{ Scenarios } \\
\hline & Base & R1-S1 & R1-S2 & $\mathrm{R} 1$ & R1-S3 & R1-S4 & R1-S5 \\
\hline Low Fragility & - & $<6.0$ & $<6.3$ & 6.0 & $<5.7$ & $<4.5$ & $<4.9$ \\
\hline Medium Fragility & - & $(6-8.5)$ & $(6.3-7.3)$ & $(6-7)$ & $(5.7-6.7)$ & $(4.5-8.5)$ & $(4.5-7)$ \\
\hline High Fragility & - & $>8.5$ & $>7.3$ & $>7.0$ & $>6.7$ & $>8.5$ & $>7.0$ \\
\hline NPV (MM U\$) & 15,996 & 15,683 & 15,587 & 15,513 & 15,502 & 15,352 & 15,228 \\
\hline Variation NPV (\%) & 0.0 & -1.8 & -2.6 & -3.0 & -3.1 & -4.0 & -4.8 \\
\hline Benefits (MM U\$) & 40,141 & 40,141 & 40,140 & 40,141 & 40,141 & 40,141 & 40,023 \\
\hline Costs (MM U\$) & 22,625 & 22,967 & 22,996 & 23,129 & 23,153 & 23,286 & 23,291 \\
\hline Available Area (Ha) & $4,316.1$ & $4,210.7$ & $4,086.9$ & $4,086.9$ & $4,077.2$ & $4,210.7$ & $4,086.9$ \\
\hline Protected Area $(\mathrm{Ha})$ & 0.0 & 105.4 & 229.2 & 229.2 & 238.9 & 105.4 & 229.2 \\
\hline Harvested Area $(\mathrm{Ha})$ & $2,802.3$ & $2,765.6$ & $2,906.2$ & $2,861.2$ & $2,846.7$ & $2,777.0$ & $2,855.6$ \\
\hline Skidders' Area (Ha) & $2,247.7$ & $1,859.8$ & $2,259.7$ & $1,977.8$ & $1,800.1$ & 917.3 & 991.0 \\
\hline Towers’ Area (Ha) & 554.7 & 905.9 & 646.5 & 883.5 & $1,046.6$ & $1,859.7$ & $1,864.6$ \\
\hline Timber $\left(\mathrm{m}^{3}\right)$ & 1.022 & 1.022 & 1.021 & 1.022 & 1.022 & 1.022 & 1.019 \\
\hline
\end{tabular}

D) SEnsitivity of RIPARIAn StRIPS. There are many watercourses in the area considered. Additional scenarios of width of riparian strips were considered as shown in Table 7.

As can be seen, for the wider strips, loss in NPV goes from $3.0 \%$ to $6.6 \%$, as highly productive land is not harvested. Note again that, if the bounds on sales are removed, as will be seen later, the loss would be higher as timber production and revenues would fall. In addition, riparian strips represent in essence a long range loss in patrimony, as these areas are excluded permanently form harvesting. Further, it is often considered that narrow riparian strips are of little use, as wind and river growths may destroy them. In this case, a 50-m strip could be considered a minimum width in some cases.

An alternative to protect watercourses is to construct post harvest barriers, $1 \mathrm{~m}$ high parallel to the watercourses. The cost of creating these barriers is estimated to be between 0.4 U.S. $\$ / \mathrm{m}^{3}$ and 1.4 U.S. $\$ / \mathrm{m}^{3}$, per $\mathrm{m}^{3}$ harvested, in use of machinery and personnel. This leads to a loss in NPV between $2.9 \%$ and $9.4 \%$. Note that, while the operational costs of barriers seem higher, these do not imply the long-range loss of patrimony caused by riparian strips. It is not clear at the moment which of the two measures is more effective in controlling water sedimentation and contamination.

In order to have an additional comparison between having riparian strips or to use barriers, we removed the upper bounds on sales, so that the loss of harvestable areas in the riparian strip scenario would reflect in the operational results. Table 8 shows the results.

TABLE 7

Sensitivity for Riparian Strips

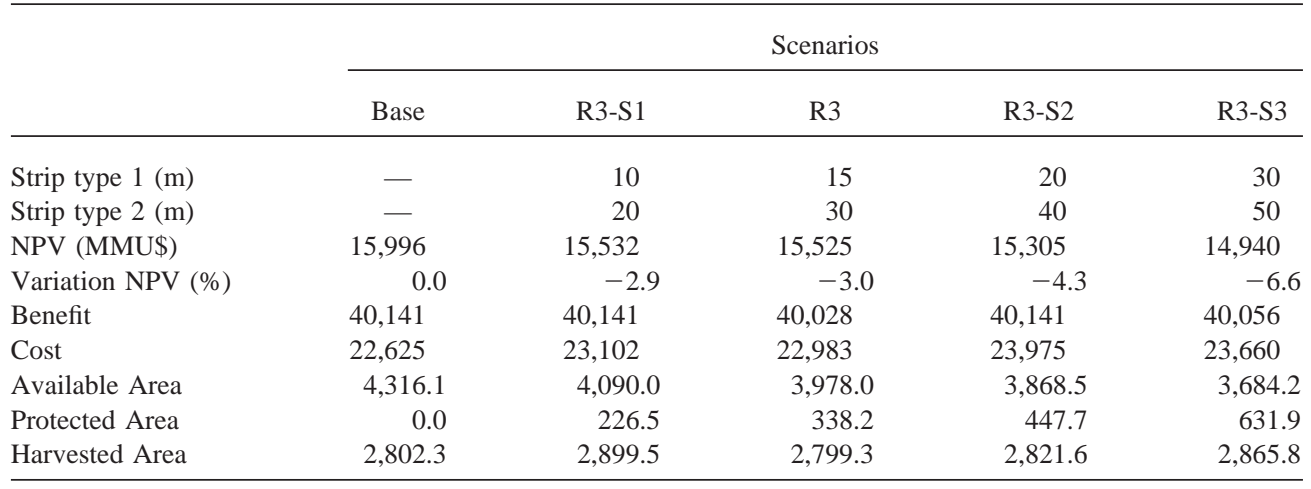


TABLE 8

Comparison of Riparian Strips (Original Widths) and Protection Barriers, No Upper Bounds on Sales

\begin{tabular}{|c|c|c|c|}
\hline & \multicolumn{3}{|c|}{ Scenarios } \\
\hline & Base & R3-Strips & Barriers \\
\hline NPV (MM U\$) & 22,686 & 20,958 & 21,405 \\
\hline Variation NPV (\%) & 0.0 & -7.6 & -5.6 \\
\hline Benefit & 60,258 & 57,414 & 61,329 \\
\hline Cost & 35,383 & 34,423 & 37,844 \\
\hline Total Production $\left(\mathrm{MM} \mathrm{m}^{3}\right)$ & 1,644 & 1,560 & 1,670 \\
\hline Available Area (Ha) & $4,316.1$ & $3,978.0$ & $4,316.1$ \\
\hline Protected Area (Ha) & 0.0 & 338.1 & 0.0 \\
\hline Harvested Area (Ha) & $4,098.8$ & $3,881.2$ & $4,191.6$ \\
\hline Skidders' Area (Ha) & $2,938.6$ & $2,821.3$ & $3,031.4$ \\
\hline Towers’ Area (Ha) & $1,160.2$ & $1,060.0$ & $1,160.2$ \\
\hline
\end{tabular}

The results show that the riparian strips (of $20 \mathrm{~m}$ and $40 \mathrm{~m}$ ) lead to a reduction of 338.1 $\mathrm{Ha}$ in harvestable area and a reduction in timber volume and revenues (and also harvesting costs, as less area is harvested). NPV for riparian strips now falls by $7.6 \%$ compared with $5.6 \%$ for barriers. This $7.6 \%$ would increase significantly if wider strips were considered.

E) Sensitivity of limiting Winter harvesting. In the basic scenarios reported in Table 3, it was seen that R4, limiting the area harvested in Winter to a fraction of the area harvested in Summer, led to a loss in NPV of $6.8 \%$. When the Winter/Summer fractions defined in Table 1 were divided by 2 (for example, for highly fragile soils harvested using towers, the fraction of Winter harvesting was reduced from 0.2 to 0.1 ), the loss in NPV was $15.3 \%$. This is mainly due to higher harvesting cost, as cable logging becomes more used. In addition, more road upgrading is needed, since now there is a constraint on the amount that can be harvested in each forest area in Winter. In order to produce the same volume in Winter, more stands must be accessible, which requires more roads to be upgraded (recall that in Winter dirt roads cannot be used). We note that the total area harvested in Summer increases as in that season more harvesting is carried out in less productive areas to allow more hectares (of productive area) to be harvested in Winter.

Adding stocking yards to stock timber from Summer to Winter reduced this impact. By considering the possibility of additional stocking at a typical cost of $3.2 \mathrm{U} . \mathrm{S} . \$ / \mathrm{m}^{3}$, the loss in NPV was reduced from $15.3 \%$ to $11.6 \%$ (still a significant level). The capacity of the stocking yard was not binding. Also, we confirmed that in the base case it is optimal not to use the stocking yards.

F) REMOVING UPPER BOUNDS ON SALES. In previous scenarios, we assumed an upper bound on sales, given by the constraints the firm has. In the sensitivity analysis of riparian strips, this constraint was removed to assess the cost of having protected areas. In the same spirit, we finally tested the final scenario (i.e., scenarios R1, R2, R3, R4, all together) with no upper bounds on sales. Table 9 shows the results. For the base case and the final scenario, we compare the results with and without imposing upper bounds on sales.

As can be seen, removing upper bounds on sales leads to a decrease in NPV of $16.6 \%$ due to the environmental measures, compared with $11.8 \%$ with upper bounds.

The main factor that explains the higher variation in NPV is the loss of harvestable land due to riparian strips and high fragility areas. If protection barriers replaced riparian strips and additional stocking yards were used to stock timber from Summer to Winter, the loss in NPV could be reduced to $10.9 \%$. 
TABLE 9

Results when all Environmental Constraints Are Implemented, With and Without Upper Bounds on Sales

\begin{tabular}{|c|c|c|c|c|}
\hline & \multicolumn{4}{|c|}{ Scenarios } \\
\hline & \multicolumn{2}{|c|}{ With Upper Bounds } & \multicolumn{2}{|c|}{ Without Upper Bounds } \\
\hline & Base & Final & Base & Final \\
\hline NPV (MMU\$) & 15,996 & 14,106 & 22,686 & 18,922 \\
\hline Variation NPV (\%) & 0.0 & -11.8 & 0.0 & -16.6 \\
\hline Benefits (MUS\$) & 40,141 & 39,982 & 60,258 & 53,974 \\
\hline Costs (MUS\$) & 22,625 & 24,482 & 35,383 & 33,264 \\
\hline Harvesting (MUS\$) & 9,657 & 10,355 & 13,962 & 12,678 \\
\hline Internal Transport (MUS\$) & 4,299 & 4,322 & 8,255 & 8,018 \\
\hline Final Transport (MUS\$) & 7,844 & 8,136 & 12,362 & 11,033 \\
\hline Road Building (MUS\$) & 50 & 112 & 97 & 130 \\
\hline Road Upgrading (MUS\$) & 777 & 1,548 & 707 & 1,404 \\
\hline Total Production $\left(\mathrm{MM} \mathrm{m}^{3}\right)$ & 1,022 & 1,018 & 1,644 & 1,463 \\
\hline Available Area (Ha) & $4,316.1$ & $3,741.7$ & $4,316.1$ & $3,741.7$ \\
\hline Protected Area (Ha) & 0.0 & 574.4 & 0.0 & 574.4 \\
\hline Harvested Area (Ha) & $2,802.3$ & $2,981.5$ & $4,098.8$ & $3,675.2$ \\
\hline Skidders' Area (Ha) & $2,247.7$ & $2,010.3$ & $2,938.6$ & $2,275.3$ \\
\hline Towers' Area (Ha) & 554.7 & 971.2 & $1,160.2$ & $1,399.9$ \\
\hline
\end{tabular}

\section{Conclusions}

We can derive several conclusions of significance from the results shown.

First, this paper illustrates the usefulness of mathematical models supported by a GIS and other data to evaluate the economic consequences of several environmental measures. This allows a political evaluation of the trade-offs between gains in environmental terms and reduced timber production or higher harvesting costs. We note that the values obtained have to be considered with limitations. We have considered a relatively short-term horizon. The model considered is in line with a long-term strategic plan, and some measures, like excluding land from harvesting, are permanent, while operational harvesting costs are not. On the other hand, we need a detailed model such as the one used here to capture the impacts of the environmental measures. Ideally, measures taken should have a high environmental impact and a low economic loss. We have evaluated, parametrically, the impact in economic and timber yields caused by several environmental measures that are typically considered. This allows us to get approximate values for the measures. Thus, considering all the scenarios analyzed, the total impact on NPV varied from $11 \%$ to $17 \%$. The results obtained allow evaluating which environmental measures have the highest impact on NPV. These are riparian strips and reduced Winter harvesting. When upper bounds on sales are removed, the loss of harvestable land can significantly reduce NPV, but this effect can be diminished by using additional stocking yards (to allow more timber stocks for Winter) and using protection barriers instead of riparian strips. Sensitivity analysis showed moderate impact on all measures, except R4, reduced Winter harvest, which can be smoothed through additional stocking yards.

In some cases, a priori protection measures can be replaced by a posteriori remedial measures. For example, instead of using more cable logging to protect fragile soils, skidders could be used and then the soil recuperated. In a study by Vega (2000), it is shown that such a measure can be worthwhile in some cases.

The values obtained give an idea of the impact of the different measures, both in absolute terms as well as in relation to each other. This allows supporting decisions on which measures have a higher impact in terms of environmental benefits and lower economic cost. As described, this process can be used in other settings and countries. 
As noted, this analysis is important in a political evaluation of new laws that is now taking place to control environmental detriment in forest management. The impacts we have described for the different proposed measures can be considered as input for the discussion process before creating final laws and regulations. This tool can be useful to the forestry firms, who are one set of actors in the negotiations, and will want to know which measures will increase more significantly their costs, as trade-offs are considered with environmental improvements. From another angle, environmental groups and the government can also gain insight on how to obtain the best environmental results consistent with measures economically viable to forestry firms. We can easily see that, once specific environmental measures have been enacted, the model presently used for planning can be modified so that the firm can make the best planning decisions incorporating the new added constraints.

Finally, we note that this type of analysis can be extended to other areas where exploitation of natural resources is carried out, such as mining and agriculture, where environmental concerns also need to be imposed, and it is important to know the costs associated to whatever measures are imposed. ${ }^{1}$

\footnotetext{
${ }^{1}$ This research was partly supported by FONDEF 1,020, and Milenium Project Complex Engineering Systems. The authors wish to acknowledge the participation of Anita Smulders (Forestal Mininco), Enrique Nieto (Forestal Valdivia), Fabian Flores (F \& F), and Fernando Bustamante (Forestal Bío Bío S.A.). The authors also wish to thank the referees and editors for their valuable suggestions.
}

\section{References}

Andalaft, N., P. Andalaft, M. Guignard, A. Magendzo, A. Wainer, and A. Weintraub (2003), “A Problem of Forest Harvesting and Road Building," Operations Research, 51, 4, 613-628.

Barret, T., J. Gilles, And L. DAvis (1998), "Economic and Fragmentation Effects of Clear-Cut Restrictions," Forest Science, 44, 4, 569-577.

CAro, F. (1999), "Evaluación Económica Mediante Modelos Matemáticos de la Implementación de Medidas Medioambientales en las Decisiones Tácticas de una Empresa Forestal,” Engineering Thesis, Industrial Engineering Department, University of Chile.

De la Maza, C. (1997), "Borrador de Impactos Ambientales de Construcción de Caminos, Cosecha y Manejo de Residuos," Proyecto Fondef 1020, Universidad de Chile y Empresas del Sector Forestal.

Ehrgott, M. And D. M. RyAn (2003), "The Method of Elastic Constraints for Multiobjective Combinatorial Optimization and Its Applications in Airline Crew Scheduling" in Multi-Objective Programming and Goal Programming, Springer Verlag, Berlin.

Epstein, R., R. Morales, J. Serón, and A. Weintraub (1999), "Use of OR Systems in the Chilean Forest Industries," Interfaces, 29, 1, 7-29.

Gayoso, J. (1997), "Producción Forestal y Conservación de Suelos,” Instituto Manejo Forestal, Universidad Austral de Chile, VIII Silviotecna.

Hof, J. AND M. Bevers (2002), "Spatial Optimization in Ecological Applications," in Complexity in Ecological Application Series, Columbia University Press, New York.

Kirby, M., W. Hager, And P. Wong (1986), "Simultaneous Planning of Wildland Transportation Alternatives" in TIMS Studies in the Management Science, Elsevier Science Publishers, New York, Vol. 21, 371-387.

Martell, D., E. GunN, AND A. Weintraub (1998), "Forest Management Challenges for Operational Researchers," European Journal of Operational Research, 104, 1-17.

Murray, A. T. and R. L. Church (1995), "Heuristic Solution Approaches to Operational Forest Planning Problems," OR Spektrum, 17, 193-203.

VEGA, R. (2000), "Metodología para Incorporar Costos de Mitigación de Impactos Medioambientales, en un Modelo de Decisión de Planificación de la Cosecha Forestas y del Transporte Forestal," Engineering Thesis, Industrial Engineering Department, University of Chile.

Weintraub, A., R. Epstein, G. Murphy, And B. Manley (2000), “The Impact of Environmental Constraints on Short Term Harvesting: Use of Planning Tools and Mathematical Models," Annals of Operations Research, $90,41-76$.

, G. Jones, A. Magendzo, M. Meacham, And M. Kirby (1994), "Heuristic System to Solve Mixed Integer Forest Planning Models," Operations Research, 42, 6, 1010-1024.

, AND D. MALChUCK (1995), "Heuristic Procedures for Solving Mixed Integer Harvest Scheduling Transportation Planning Models," Canadian Journal of Forest Research, 25, 16181626. 
Felipe Caro is Instructor at the Department of Industrial Engineering, University of Chile. This research was part of his engineering thesis. He is presently pursuing his Ph.D. in Operations Management at the Sloan School of Business of Massachusetts Institute of Technology. He can be reached by e-mail at fcaro@dii.uchile.cl.

Rodrigo Andalaft has degrees in Civil Industrial Engineering and Civil Computer Engineering from the University of Chile. He participated in the research leading to this paper in his Engineering thesis. Presently, he is Head of the Department of Financial Information at the Consorcio Nacional de Seguros Vida, a large insurance company, where he has developed mathematical models and information systems to evaluate and price insurance products. He can be reached by e-mail at Rodrigo.andalaft@ consorcio.cl.

Ximena Silva is a Civil Industrial Engineer of the University of Chile. The research leading to this paper was part of her Engineering thesis. Since graduating in 1998, she has worked at ENDESA (National Electricity Enterprise) as an engineering analyst in themes such as programming energy loads, client evaluation, and budgets.

Andres Weintraub is a Civil Electrical Engineer, University of Chile, M.A. in Statistics and Ph.D. in Industrial Engineering-Operations Research from the University of California, Berkeley. He is Professor at the Department of Industrial Engineering, University of Chile. His research interests are in Forestry Models, Transportation, Applied Combinatorics, and Operations Management, and he has published about 50 papers in these areas. He was awarded the National Prize in Applied Science and Technology of Chile in 2000 and the Harold Larnder Prize 2000, by the Canadian Society of Operations Research. He was part of the team that won the INFORMS Edelman Prize Competition in 1998.

Pedro Sapunar is a Forest Engineer of the University of Chile. He is currently Head of the Department of Production Planning in Bosques Arauco S.A. He is also chair of the Committee of Planning and Roads at CORMA, the Chilean Timber Corporation and is Regional President of the Association of Forest Engineering. He has participated in many projects related to forest optimization models, and environmental management, leading to over 20 publications in specialized journals and seminars. He can be reached by e-mail at psapunar@arauco.cl.

Manuel Cabello is a Forest Engineer from the Austral University in Chile. He is currently Head of the Division of Informatics at Forestal Millalemu. During the development of this research project, he headed the group at Forestal Millalemu. 
Copyright of Production \& Operations Management is the property of Production Operations Management Society and its content may not be copied or emailed to multiple sites or posted to a listserv without the copyright holder's express written permission. However, users may print, download, or email articles for individual use. 